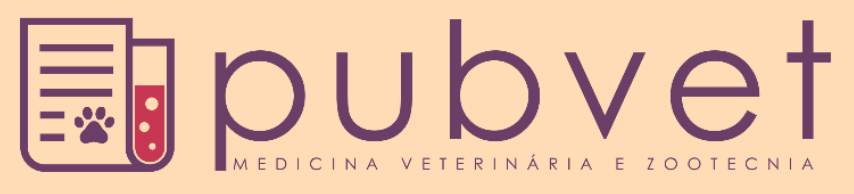

https://doi.org/10.31533/pubvet.v13n3a281.1-7

\title{
Produtividade de forragem e características morfogênicas e estruturais de Megathyrsus maximus cv. Zuri sob níveis de desfolhação
}

\author{
Newton de Lucena Costa ${ }^{\ominus *}$, Liana Jank ${ }^{\oplus 2}$, João Avelar Magalhães ${ }^{\ominus}$, Antônio Neri \\ Azevedo Rodrigues ${ }^{\bullet}$, Amaury Burlamaqui Bendahan ${ }^{\ominus}$, Fabíola Helena dos Santos \\ Fogaça 5, Francisco José de Seixas Santos ${ }^{0}$
}

${ }^{1}$ Eng. Agr., D.Sc., Pesquisador da Embrapa Roraima, Boa Vista, RR.

${ }^{2}$ Eng. Agr., Ph.D., Pesquisadora da Embrapa Gado de Corte, Campo Grande, MS.

${ }^{3}$ Méd. Vet., Pesquisador da Embrapa Meio-Norte, Parnaíba, PI.

${ }^{4}$ Eng. Agr., D.Sc., Professor do Instituto Federal de Rondônia, Colorado do Oeste, RO.

${ }^{5}$ Zootecnista, D.Sc., Pesquisadora da Embrapa Meio-Norte, Parnaíba, PI.

${ }^{6}$ Eng. Agr., D.Sc., Pesquisador da Embrapa Meio-Norte, Parnaíba, PI.

*Autor para correspondência,E-mail: newtonlucena@yahoo.com.br

Resumo. O efeito do nível de desfolhação (20,30, 40 e $50 \mathrm{~cm}$ acima do solo) sobre a produção de forragem e características morfogênicas e estruturais de Megathyrsus maximus cv. Zuri foi avaliado nos cerrados de Roraima. Os efeitos dos níveis de desfolhação sobre a produção de matéria seca verde, índice de área foliar e taxa de expansão de folhas foram ajustados ao modelo quadrático de regressão e os máximos valores registrados com cortes a 42,7; 42,2 e 41,1 cm acima do solo, respectivamente. A densidade populacional de perfilhos, taxa de aparecimento de folhas e número de folhas perfilho ${ }^{-1}$ foram inversamente proporcionais ao nível de desfolhação, ocorrendo o inverso quanto ao comprimento médio de folhas e taxa de senescência foliar. A eliminação de meristemas apicais foi incrementada com o aumento do nível de desfolhação. $\mathrm{O}$ vigor de rebrota foi direta e negativamente correlacionado com o nível de desfolhação. Pastagens de M. maximus cv. Zuri manejadas sob resíduo de $40 \mathrm{~cm}$ proporciona maior produtividade e eficiência de utilização da forragem, maior renovação de tecidos e estrutura do dossel mais favorável ao pastejo.

Palavras chave: Folhas, matéria seca verde, perfilhamento, senescência

\section{Forage yield and morphogenetic and structural characteristics of Megathyrsus maximus cv. Zuri under defoliation levels}

\begin{abstract}
The effects of defoliation level (20,30, 40 and $50 \mathrm{~cm}$ above soil level) on green dry matter (GDM) yield and morphogenetic and structural characteristics of Megathyrsus maximus cv. Zuri were evaluated under field conditions in Roraima's savannas. The effects of defoliation level on the GDM yields, leaf area index and leaf elongation rates was adjusted to the quadratic regression model and maximum values recorded with cutting at $42.7 ; 42.2$ and $41.1 \mathrm{~cm}$ above soil level, respectively. The population tiller density, number of leaves plant $^{-1}$ and leaf appearance rate was inversely proportional to the level of defoliation, while the opposite occurred for to medium blade length and leaf senescence rate. Apical meristem removing percentage was higher with increasing defoliation level. Aftermath regrowth showed close negative correlation with defoliation level. Pastures of M. maximus cv. Zuri managed under $40 \mathrm{~cm}$ residue provides higher forage productivity, larger efficiency of forage utilization, greater tissue renewal and canopy structure more favorable to grazing.
\end{abstract}

Keywords: Green dry matter, leaves, tillering, senescence 


\section{Producción de forraje y características morfogenéticas y estructurales de Megathyrsus maximus cv. Zuri bajo niveles de defoliación}

Resumen. El efecto de niveles de defoliación (20, 30, 40 y $50 \mathrm{~cm}$ por encima del suelo) sobre la producción de forraje y características morfogenéticas y estructurales de Megathyrsus maximus cv. Zuri se evaluó en las sabanas de Roraima. Los efectos de los niveles de defoliación sobre la producción de materia seca verde, índice de área foliar y tasa de expansión de hojas fueron ajustados al modelo cuadrático de regresión y los máximos valores registrados con cortes a 42,7; 42,2 y 41,1 cm por encima del suelo, respectivamente. La densidad poblacional de macollas, la tasa de aparición de hojas y el número de hojas macolla ${ }^{-1}$ fueron inversamente proporcional al nivel de defoliación, ocurriendo lo contrario en cuanto a la longitud media de las hojas y la tasa de senescencia foliar. La eliminación de meristemos apicales se incrementó con el aumento del nivel de defoliación. El vigor de rebrote fue directo y negativamente correlacionado con el nivel de defoliación. Pastos de M. maximus cv. Zuri manejados bajo residuo de $40 \mathrm{~cm}$ proporciona mayor productividad y eficiencia de utilización del forraje, mayor renovación de tejidos y estructura del dosel más favorable al pastoreo.

Palabras clave: Hojas, materia seca verde, macollamiento, senescencia

\section{Introdução}

Em Roraima, as pastagens cultivadas representam o mais importante recurso forrageiro para a alimentação dos rebanhos bovinos. A utilização do pastejo contínuo associado a períodos mínimos de descanso, altas intensidades de desfolhação e a não reposição dos nutrientes removidos via produção animal são fatores determinantes para a baixa disponibilidade e qualidade da forragem, com reflexos negativos nos índices de desempenho zootécnico dos animais (Costa et al., 2007). A produtividade e a perenidade das gramíneas forrageiras decorrem de sua capacidade de reconstituição e manutenção da área foliar após a desfolhação, a qual afeta a estrutura do dossel, determinando sua velocidade de crescimento (Pereira, 2013). O estádio de crescimento da gramínea está estreitamente correlacionado com o acúmulo de forragem, como decorrência das alterações morfológicas e fisiológicas que condicionam o balanço entre produção e senescência de tecidos, com reflexos na composição química, capacidade de rebrota e persistência da pastagem (Nabinger \& Carvalho, 2009).

O ponto central do manejo do pastejo consiste em mediar o encontro planta-animal e determinar a eficiência entre o crescimento da planta, o seu consumo e a produção animal para manter estável o sistema de produção (Hodgson, 1990). O equilíbrio entre produtividade e qualidade deve ser alcançado, visando assegurar os requerimentos nutricionais dos animais e garantindo, simultaneamente, a maximização da eficiência dos processos de produção, utilização e conversão da forragem produzida. A intensidade de manejo condiciona diferenças na estrutura da pastagem que afetam o processo de desfolhação pelo animal e modificam a dinâmica de crescimento da pastagem com influências sobre os fluxos de biomassa (Pontes et al., 2004). A intensidade de desfolhação representa a proporção do tecido vegetal removido pelo animal em comparação ao disponibilizado para pastejo, impactando a área foliar fotossinteticamente ativa remanescente, à remobilização de reservas orgânicas e a remoção de meristemas apicais (Lemaire et al., 2011).

A visualização da curva estacional de produção de forragem e a possibilidade de predição de sua composição química e/ou valor nutritivo pode ser estimada por meio do conhecimento das características morfogênicas e estruturais (Alexandrino et al., 2011; Ferreira, 2017), a qual pode auxiliar na proposição de práticas de manejo específicas para cada gramínea forrageira, visando maximizar a eficiência de utilização da pastagem (Pereira, 2013; Santos et al., 2012). A morfogênese descreve a dinâmica da geração e expansão dos tecidos e órgãos da gramínea no tempo e espaço, sendo sintetizada por três variáveis: a taxa de aparecimento, a taxa de alongamento e a duração de vida das folhas, as quais, apesar de sua natureza genética, são fortemente influenciadas pelas condições ambientais (temperatura, luz, água e fertilidade do solo) e práticas de manejo. As interações entre estas variáveis afetam as características estruturais: número de folhas vivas perfilho ${ }^{-1}$ (NFV), comprimento médio de 
folhas (CMF) e densidade de perfilhos, as quais determinarão o índice de área foliar (IAF), ou seja, o aparato utilizado para a interceptação da radiação pelo dossel da pastagem. O NFV reflete a taxa de aparecimento e a duração de vida das folhas, sendo determinado geneticamente, enquanto que a taxa de alongamento foliar condiciona o CMF (Lemaire et al., 2011).

Neste trabalho avaliou-se o efeito de níveis de desfolhação sobre a produção de forragem e características morfogênicas e estruturais de pastagens de Megathyrsus maximus cv. Zuri nos cerrados de Roraima.

\section{Material e métodos}

O ensaio foi conduzido no Campo Experimental da Embrapa Roraima, localizado em Boa Vista, durante o período de maio a setembro de 2015 , o qual correspondeu a uma precipitação acumulada de $1.218 \mathrm{~mm}$ e temperatura média mensal de $24,9^{\circ} \mathrm{C}$. O solo da área experimental é um Latossolo Amarelo, textura média, fase cerrado, com as seguintes características químicas, na profundidade de $0-20 \mathrm{~cm}$ : $\mathrm{pH}_{\mathrm{H} 2 \mathrm{O}}=5,7 ; \mathrm{P}=11,5 \mathrm{mg} / \mathrm{kg} ; \mathrm{Ca}+\mathrm{Mg}=1,15 \mathrm{cmol}_{\mathrm{c}} \cdot \mathrm{dm}^{-3} ; \mathrm{K}=0,019 \mathrm{cmol}_{\mathrm{c}} \cdot \mathrm{dm}^{-3}$ e $\mathrm{Al}=0,17 \mathrm{cmol}_{\mathrm{c}} \mathrm{dm}^{-3}$.

$\mathrm{O}$ delineamento experimental foi em blocos ao acaso com três repetições e os tratamentos representados por quatro níveis de desfolhação $(20,30,40$ e $50 \mathrm{~cm}$ acima do solo). As parcelas mediam 2,0 x 2,0 m, sendo a área útil de $1,0 \mathrm{~m}^{2}$. A adubação de estabelecimento constou da aplicação de $50 \mathrm{~kg}$ de $\mathrm{P}_{2} \mathrm{O}_{5}$ ha $^{-1}$ e $60 \mathrm{~kg}$ de $\mathrm{K}_{2} \mathrm{O}$ ha ${ }^{-1}$, respectivamente sob a forma de superfosfato triplo e cloreto de potássio. Durante o período experimental foram realizados quatro cortes a intervalos de 35 dias.

Os parâmetros avaliados foram rendimento de matéria seca verde (MSV), densidade populacional de perfilhos (DPP), número de folhas vivas perfilho ${ }^{-1}$ (NFV), taxa de aparecimento de folhas (TAF), taxa de expansão foliar (TEF), taxa de senescência foliar (TSF), comprimento médio de folhas (CMF) e índice de área foliar (IAF). A TEF e TAF foram obtidas dividindo-se o comprimento acumulado de folhas e o número total de folhas perfilho ${ }^{-1}$, respectivamente, pelo período de rebrota. O CMF foi determinado pela divisão do alongamento foliar total do perfilho pelo seu número de folhas. Para o cálculo da área foliar, em cada idade de rebrota foram coletadas amostras de folhas verdes completamente expandidas, procurando-se obter uma área entre 200 e $300 \mathrm{~cm}^{2}$, sendo estimada com planímetro ótico eletrônico (Li-Cor, modelo LI-3100C). Posteriormente, as amostras foram levadas à estufa com ar forçado a $65^{\circ} \mathrm{C}$ até atingirem peso constante, obtendo-se a MS foliar. A área foliar específica (AFE) foi determinada através da relação entre área de folhas verdes e sua $\mathrm{MS}\left(\mathrm{m}^{2} / \mathrm{g} \mathrm{MS}\right.$ foliar). O IAF foi determinado a partir do produto entre a MS total das folhas verdes ( $\mathrm{g}$ de $\mathrm{MS} / \mathrm{m}^{2}$ ) pela AFE $\left(\mathrm{m}^{2} / \mathrm{g}\right.$ de MS foliar). A TSF foi obtida dividindo-se o comprimento da folha que se apresentava de coloração amarelada ou necrosada pelo período de rebrota. A sobrevivência dos meristemas apicais foi estimada relacionando-se com o número total de perfilhos aqueles que se apresentavam com folhas novas truncadas, sete dias após o corte das plantas. O vigor de rebrota foi avaliado através da produção de MSV decorridos 21 dias após o primeiro corte.

Os dados foram submetidos à análise de variância e de regressão considerando o nível de significância de $5 \%$ de probabilidade. Para se estimar a resposta dos parâmetros avaliados aos níveis de desfolhação, a escolha dos modelos de regressão baseou-se na significância dos coeficientes linear e quadrático, por meio do teste " $t$ ", de Student, ao nível de 5\% de probabilidade.

\section{Resultados e discussão}

A relação entre rendimento de MSV e os níveis de desfolhação foi ajustada ao modelo quadrático de regressão e o máximo valor estimado com cortes a $42,7 \mathrm{~cm}$ acima do solo (Tabela 1). O efeito imediato do nível de desfolhação sobre o crescimento da gramínea é a redução de sua área foliar e, consequentemente, da capacidade em interceptar luz e redução global da fotossíntese, processos que são afetados pela proporção de tecido removido; o grau de desfolha das plantas vizinhas e a eficiência fotossintética do tecido foliar remanescente após a desfolhação (Canto et al., 2008; Costa et al., 2006; Pereira, 2013). A desfolhação implica em rápido declínio na quantidade de carboidratos solúveis disponibilizados para o crescimento das raízes da gramínea, como consequência da redução em sua taxa fotossintética como um todo e alocação preferencial de carbono para as partes áreas da planta com a 
finalidade de restaurar sua área foliar (Costa et al., 2008; Lemaire et al., 2011; Santos et al., 2011). Os rendimentos de MSV, para todos os níveis de desfolhação, foram superiores ao sugerido por Minson (2012) como limite mínimo de forragem disponível em pastagens de gramíneas tropicais $\left(2.000 \mathrm{~kg} \mathrm{ha}^{-1}\right)$, de modo a não restringir o acesso e o consumo voluntário de forragem pelos animais.

A retenção de maior área foliar fotossinteticamente ativa e a maior remobilização de nutrientes com a redução na intensidade de desfolhação, proporciona maior velocidade de recuperação e menor intervalo entre pastejos (Cecato et al., 2000; Nabinger \& Carvalho, 2009; Pereira, 2013). Costa et al. (2008) obtiveram maiores rendimentos de MSV para pastagens de M. maximus cv. Centenário manejadas sob resíduos de $40 \mathrm{~cm}\left(4.855 \mathrm{~kg} \mathrm{ha}^{-1}\right)$, comparativamente a $30 \mathrm{~cm}\left(3.411 \mathrm{~kg} \mathrm{ha}^{-1}\right)$ ou $20 \mathrm{~cm}$ acima do solo (2.108 $\left.\mathrm{kg} \mathrm{ha}^{-1}\right)$. Para pastagens de M. maximus cv. Tanzânia-1, Canto et al. (2008) constataram incrementos lineares na disponibilidade de forragem com a redução do nível de desfolhação (2.810; 3.155; 3.678 e $4.110 \mathrm{~kg}$ de $\mathrm{MS} \mathrm{ha}^{-1}$, respectivamente para 20, 40, 60 e $80 \mathrm{~cm}$ acima do solo). Comportamento semelhante foi relatado por José et al. (2017) para pastagens de M. maximus cv. Vencedor $\left(4.255 ; 3.875\right.$ e $3.211 \mathrm{~kg}$ de $\mathrm{MS} \mathrm{ha}^{-1}$, respectivamente para níveis de desfolhação de 40; 50 e $60 \%)$.

Tabela 1. Rendimento de matéria seca verde (MSV - $\left.\mathrm{kg} \mathrm{ha}^{-1}\right)$, remoção de meristemas apicais (RMA - \%), vigor de rebrota (VR - kg MSV/21 dias), densidade populacional de perfilhos $\mathrm{m}^{-2}$ (DPP), número de folhas vivas perfilho ${ }^{-1}$ (NFP), comprimento médio de folhas (CMF - cm), índice de área foliar $\left(\mathrm{IAF}-\mathrm{m}^{2} / \mathrm{m}^{2}\right)$, taxa de aparecimento de folhas (TAF - folhas perfilho ${ }^{-1} \mathrm{dia}^{-1}$ ), taxa de expansão foliar (TEF - cm perfilho-1 $\mathrm{dia}^{-1}$ ) e taxa de senescência foliar (TSF - cm perfilho ${ }^{-1}$ dia $^{-1}$ ) de Megathyrsus maximus cv. Zuri, em função do nível de desfolhação. Médias de quatro cortes

\begin{tabular}{|c|c|c|c|c|c|}
\hline \multirow{2}{*}{ Variáveis } & \multicolumn{4}{|c|}{ Nível de Desfolhação (cm) } & \multirow{2}{*}{ Equação de Regressão } \\
\hline & 20 & 30 & 40 & 50 & \\
\hline MSV & 3.345 & 3.922 & 4.791 & 4.355 & $\mathrm{Y}=-47,15+216,27 \mathrm{X}-2,5325 \mathrm{X}^{2}\left(\mathrm{R}^{2}=0,88\right)$ \\
\hline RMA & 47,2 & 39,8 & 33,7 & 29,1 & $\mathrm{Y}=41,92-0,6263 \mathrm{X}\left(\mathrm{r}^{2}=0,91\right)$ \\
\hline VR & 1.278 & 1.657 & 2.011 & 1.854 & $Y=-502,7+114,62 X-1,3413 X^{2}\left(R^{2}=0,94\right)$ \\
\hline DPP & 298 & 256 & 221 & 197 & $Y=360,5-3,351 X\left(r^{2}=0,92\right)$ \\
\hline NFV & 5,94 & 5,37 & 4,85 & 4,59 & $Y=6,78-0,0457 X\left(r^{2}=0,95\right)$ \\
\hline $\mathrm{CMF}$ & 31,12 & 37,02 & 42,89 & 44,11 & $Y=23,91+0,4484 X\left(r^{2}=0,94\right)$ \\
\hline IAF & 2,78 & 3,55 & 4,64 & 4,07 & $\mathrm{Y}=1,74+0,2871 \mathrm{X}-0,00346 \mathrm{X}^{2}\left(\mathrm{R}^{2}=0,90\right)$ \\
\hline TAF & 0,170 & 0,153 & 0,139 & 0,131 & $\mathrm{Y}=0,11938-0,0013 \mathrm{X}\left(\mathrm{r}^{2}=0,95\right)$ \\
\hline TEF & 5,282 & 5,680 & 5,943 & 5,785 & $\mathrm{Y}=3,52+0,11521 \mathrm{X}-0,00141 \mathrm{X}^{2}\left(\mathrm{R}^{2}=0,92\right)$ \\
\hline TSF & 0,133 & 0,161 & 0,195 & 0,213 & $\mathrm{Y}=0,0796+0,00272 X\left(\mathrm{r}^{2}=0,88\right)$ \\
\hline
\end{tabular}

Os níveis de desfolhação afetaram negativa e linearmente a remoção de meristemas apicais (Tabela 1). Para pastagens de $M$. maximus cv. Tanzânia-1, Cecato et al. (2000) estimaram maior remoção de meristemas apicais com cortes a $20 \mathrm{~cm}$ acima do solo (40,1\%), comparativamente a $40(35,5 \%)$, a qual foi negativamente correlacionada com a produção de forragem. $\mathrm{O}$ vigor de rebrota foi afetado $(\mathrm{P}<0,05)$ pelo nível de desfolhação, sendo a relação quadrática e o máximo rendimento de MSV estimado com cortes a 41,22 cm acima do solo. Costa et al. (2008) reportaram que o vigor de rebrota de M. maximus cv. Vencedor foi diretamente proporcional ao nível de desfolhação $(1.233 ; 1.579$ e $1.977 \mathrm{~kg}$ de MSV/21 dias, respectivamente para cortes a 30,40 e $50 \mathrm{~cm}$ acima do solo). A reconstituição da área foliar das gramíneas, após o processo de desfolhação, apresenta alta correlação com a remoção de meristemas apicais e, quanto maior for sua intensidade, maior será o tempo demandado para o novo crescimento, originado a partir do desenvolvimento de gemas axilares ou basilares, as quais apresentam menor velocidade de diferenciação e expansão (Lemaire et al., 2011; Pereira, 2013). Para pastagens de $M$. maximus cv. Tanzânia-1, Cecato et al. (2000) reportaram maior VR com cortes a $40 \mathrm{~cm}$ acima do solo (9.124 kg de MS/21 dias) comparativamente a $20 \mathrm{~cm}$ (7.308 kg de MS/21 dias).

Os efeitos dos níveis de desfolhação sobre CMF e o NFV foram positivos e lineares, enquanto que para o IAF o modelo ajustado de regressão foi o quadrático e o máximo valor estimado com desfolhações a $42,21 \mathrm{~cm}$ acima do solo. Os valores registrados para o NFV e CMF foram superiores aos reportados por Macedo et al. (2010) para pastagens de M. maximus cv. Mombaça manejadas sob resíduo de $25 \mathrm{~cm}$, que estimaram 3,95 folhas perfilho ${ }^{-1}$ e $34,5 \mathrm{~cm}$ folha ${ }^{-1}$, ocorrendo o inverso quanto ao IAF $(10,40)$. O CMF é 
a característica plástica mais responsiva ao nível de desfolhação e considerada a estratégia morfológica de escape das plantas ao pastejo. Em geral, menores valores para o CMF foram constatados com maiores níveis de desfolhação, provavelmente em decorrência na redução da fase de multiplicação celular e da distância que a lâmina foliar deveria percorrer até a emergência do pseudocolmo (Lemaire et al., 2011).

O NFV é a característica morfogênica que apresenta maior correlação com a duração de vida da folha, a qual é de grande relevância para o manejo da pastagem, representando uma estimativa do teto potencial de rendimento da gramínea (máxima quantidade de biomassa verde por área), além de ser um indicador prático para a determinação da intensidade de pastejo no sistema de lotação contínua ou da frequência do pastejo no sistema de lotação intermitente que permite a obtenção de IAF próximos da maior eficiência de intercepção luminosa e máximas taxas de crescimento (Nabinger \& Carvalho, 2009). O IAF sintetiza a funcionalidade das características morfogênicas e estruturais e representa o balanço dos processos que determinam a oferta (fotossíntese) e a demanda (respiração, acúmulo de reservas, síntese e senescência de tecidos) de fotoassimilados, estabelecendo o ritmo de crescimento da pastagem (Pereira, 2013). A arquitetura do dossel interfere na interceptação e distribuição da luz dentro da população de plantas, bem como na circulação de ar, afetando os processos de transferência de $\mathrm{CO}_{2}$ e a evapotranspiração, sendo possível inferir que pequenas diferenças na altura das plantas podem ter grandes efeitos na competição por luz, pois uma diferença mínima é suficiente para uma folha sobreporse à outra (Souza, 2018).

A DPP foi linear e inversamente proporcional ao nível de desfolhação (Tabela 1). O perfilhamento representa característica estrutural fortemente influenciada por fatores nutricionais, ambientais e de manejo, os quais definem as características morfogênicas que condicionam a resposta morfogênica das plantas forrageiras aos sistemas de manejo (Cecato et al., 2000, Garcez Neto et al., 2002). A emissão de novos perfilhos é um processo constante e potencializado quando a gramínea é desfolhada como consequência da melhoria do ambiente luminoso na base do dossel (maior razão da radiação vermelha:vermelha distante), o qual é intermediado por dois fatores principais: o suprimento de energia para a fotossíntese e o número e atividade de pontos de crescimento (Gastal \& Lemaire, 2002; Nabinger \& Carvalho, 2009). Em pastagens de M. maximus cv. Centenário, Costa et al. (2006) estimaram maiores DPP para desfolhações a $20 \mathrm{~cm}\left(478\right.$ perfilhos $\left.\mathrm{m}^{-2}\right)$, comparativamente a $30 \mathrm{~cm}\left(381\right.$ perfilhos $\left.\mathrm{m}^{-2}\right)$ ou $40 \mathrm{~cm}$ acima do solo (237 perfilhos $\mathrm{m}^{-2}$ ).

O efeito dos níveis de desfolhação sobre a TEF foi ajustado ao modelo quadrático de regressão e o máximo valor estimado com cortes a $41,1 \mathrm{~cm}$ acima do solo, enquanto que para a TAF a relação foi linear e negativa (Tabela 1). As folhas de menor tamanho, em geral, estão associadas a maiores valores de TAF, enquanto que a TEF apresenta correlação positiva e significativa com o CMF (Nabinger \& Carvalho, 2009, Pereira, 2013). A TAF pode ser reconhecida como a característica morfogênica que merece maior relevância, pois afeta diretamente o CMF, a DPP e o NFV (Nabinger \& Pontes, 2002; Difante et al., 2011). As TAF e TEF, geralmente, apresentam correlação negativa, pois quanto mais rápido ocorre o aparecimento de folhas, menor será o tempo disponibilizado para sua completa expansão e diferenciação (Pereira, 2013; Nascimento, 2014).

Os níveis de desfolhação afetaram positiva e linearmente a TSF (Tabela 1). Costa et al. (2007) reportaram maiores TSF para pastagens de M. maximus $\mathrm{cv}$. Vencedor sob resíduos de $50 \mathrm{~cm}(0,273 \mathrm{~cm}$ perfilho $\left.\mathrm{dia}^{-1}\right)$ ou $40 \mathrm{~cm}\left(0,211 \mathrm{~cm}_{\text {perfilho }} \mathrm{dia}^{-1}\right)$, comparativamente a $30 \mathrm{~cm}\left(0,196 \mathrm{~cm}_{\text {perfillho }} \mathrm{dia}^{-1}\right)$. A senescência representa processo natural que caracteriza a última fase de desenvolvimento da folha, iniciada após sua completa expansão, cuja intensidade se acentua progressivamente com o aumento do IAF e do CMF, em função do sombreamento das folhas dispostas na porção inferior da planta e do baixo suprimento de radiação fotossinteticamente ativa, além de forte competição por luz, nutrientes e água (Ferlin et al., 2006, Nabinger \& Carvalho, 2009). Com a estabilização do NFV ocorre equilíbrio entre a TAF e a senescência das folhas que ultrapassaram seu período de duração de vida, de forma que para o surgimento de nova folha deve ocorrer a senescência da folha precedente visando manter o NFV relativamente constante (Lemaire et al., 2011, Rodrigues et al., 2012). Destarte o efeito negativo da senescência sobre a qualidade da forragem, ela representa importante processo fisiológico no fluxo de tecidos da gramínea, pois em torno de 35; 68; 86 e 42\% do nitrogênio, fósforo, potássio e magnésio, respectivamente, podem ser reciclados das folhas senescentes e utilizados para a produção de novos tecidos foliares (Sarmiento et al., 2006). 


\section{Conclusões}

O nível de desfolhação afeta a produção de forragem e as características morfogênicas e estruturais da gramínea. A eliminação de meristemas apicais é diretamente proporcional ao nível de desfolhação, ocorrendo o oposto quanto ao vigor de rebrota. A pastagem de M. maximus cv. Zuri manejada sob resíduo de $40 \mathrm{~cm}$ proporciona maior produtividade e eficiência de utilização da forragem, maior renovação de tecidos e estrutura do dossel mais favorável ao pastejo.

\section{Referências bibliográficas}

Alexandrino, E., Cândido, M. J. D. \& Gomide, J. A. (2011). Fluxo de biomassa e taxa de acúmulo de forragem em capim Mombaça mantido sob diferentes alturas. Revista Brasileira de Saúde e Produção Animal, 12(1):59-71.

Canto, M. W., Jobim, C. C., Gasparino, E. \& Hoeschl, A. R. (2008). Características do pasto e acúmulo de forragem em capim-tanzânia submetido a alturas de manejo do pasto. Pesquisa Agropecuária Brasileira, 43(3):429-435.

Cecato, U., Machado, A. O., Martins, E. N., Pereira, L. A. F., Barbosa, M. A. A. \& Santos, G. T. (2000). Avaliação da produção e de algumas características da rebrota de cultivares e acessos de Panicum maximum Jacq. sob duas alturas de corte. Revista Brasileira de Zootecnia, 29(3):660-668.

Costa, N. L., Magalhães, J. A., Pereira, R. G. A., Townsend, C. R. \& Oliveira, J. R. C. (2007). Considerações sobre o manejo de pastagens na Amazônia Ocidental. Revista do Conselho Federal de Medicina Veterinária, 40(1):37-56.

Costa, N. L., Paulino, V. T., Magalhães, J. A., Townsend, C. R. \& Pereira, R. G. A. (2008). Morfogênese de gramíneas forrageiras na Amazônia Ocidental. PUBVET, 2:1-24.

Costa, N. L., Townsend, C. R. \& Avelar, J. (2006). Formação e manejo de pastagens na Amazônia do Brasil. Revista Electrónica de Veterinária, 7:1-18.

Difante, G. S., Nascimento Júnior, D., Silva, S. C., Euclides, V. P. B. \& Montagner, D. B. (2011). Características morfogênicas e estruturais do capim-marandu submetido a combinações de alturas e intervalos de corte. Revista Brasileira de Zootecnia, 40(7):955-963.

Ferreira, M. R. (2017). Análise de repetibilidade e agrupamentos em genótipos de Panicum maximum Jacq. 69 f. Dissertação (Mestrado em Zootecnia). Universidade Federal dos vales do Jequitinhonha e Mucuri.

Ferlin, M. B., Euclides, V. P. B., Lempp, B., Gonçalves, M. C. \& Cubas, A. C. (2006). Morfogênese e dinâmica do perfilhamento de Panicum maximum Jacq. cv. Tanzânia sob pastejo. Ciência e Agrotecnologia, 30(3):344-352.

Garcez Neto, A., Nascimento Júnior, D. \& Regazzi, A. J. (2002). Respostas morfogênicas e estruturais de Panicum maximum cv. Mombaça sob diferentes níveis de adubação nitrogenada e alturas de corte. Revista Brasileira de Zootecnia, 31:1890-1900.

Gastal, F. \& Lemaire, G. (2002). N uptake and distribution in crops: an agronomical and ecophysiological perspective. Journal of Experimental Botany, 53:789-799.

Hodgson, J. (1990). Grazing management. Science into practice. London: Longman Group UK Ltd. 203p.

José, R. M., Mocelin, N. G. \& Zanini, G. D. (2017). Avaliações agronômicas em pastos de capim Aruana submetidos a três proporções de desfolha. Paper presented at the VIII Seminário de Ensino, Pesquisa e Extensão do UNIBAVE-SENPEX III Feira de Tecnologia e Inovação "A produção do conhecimento e o fortalecimento do elo entre ensino, pesquisa e extensão" Orleans, Santa Catarina.

Lemaire, G., Hodgson, J. \& Chabbi, A. (2011). Grassland productivity and ecosystem services (Vol. 1). Wallingford: Cabi. 287p.

Macedo, C. H. O., Alexandrino, E., Jakelaitis, A., Vaz, R. G. M. V., Reis, R. H. P. \& Vendrusculo, J. (2010). Características agronômicas, morfogênicas e estruturais do capim" Panicum maximum" cv. Mombaça sob desfolhação intermitente. Revista Brasileira de Saúde e Produção Animal, 11(4):941952. 
Minson, D. (2012). Forage in ruminant nutrition (Vol. 1). New York: Academic Press. 502p.

Nabinger, C. \& Carvalho, P. F. C. (2009). Ecofisiología de sistemas pastoriles: aplicaciones para su sustentabilidad. Agrociencia, 13(3):18-27.

Nabinger, C. \& Pontes, L. S. (2002). Manejo da desfolha. Simpósio sobre manejo da pastagem. FEALQ, Jaboticabal. p.231-251.

Nascimento, H. L. B. (2014). Cultivares de Panicum maximum adubadas e manejadas com frequência de desfolhação correspondente a 95\% de interceptação luminosa. 67 f. Dissertação. (Mestrado em Zootecnia). Universidade Federal de Viçosa.

Pereira, V. V. (2013). A importância das características morfogênicas sobre o fluxo de tecidos no manejo de pastagens tropicais. Revista em Agronegócio e Meio Ambiente, 6(2):289-309.

Pontes, L. S., Carvalho, P. C. F., Nabinger, C. \& Soares, A. B. (2004). Fluxo de biomassa em pastagem de azevém anual (Lolium multiflorum Lam.) manejada em diferentes alturas. Revista Brasileira de Zootecnia, 33(2):529-537.

Rodrigues, C. S., Nascimento Júnior, D., Silveira, M. C. T., Sousa, B. M. d. L., Silva, S. C. \& Detmann, E. (2012). Grupos funcionais de gramíneas forrageiras tropicais. Revista Brasileira de Zootecnia, 41(8):1385-1393.

Santos, M. E. R., Fonseca, D. M., Braz, T. G. S., Silva, S. P., Gomes, V. M. \& Silva, G. P. (2011). Características morfogênicas e estruturais de perfilhos de capim-braquiária em locais do pasto com alturas variáveis. Revista Brasileira de Zootecnia, 40(3):535-542.

Santos, M. E. R., Fonseca, D. M., Gomes, V. M., Silva, S. P., Silva, G. P. \& Reis, M. (2012). Correlações entre características morfogênicas e estruturais em pastos de capim-braquiária. Ciência Animal Brasileira, 13(1):49-56.

Sarmiento, G., Silva, M. P., Naranjo, M. E. \& Pinillos, M. (2006). Nitrogen and phosphorus as limiting factors for growth and primary production in a flooded savanna in the Venezuelan Llanos. Journal of Tropical Ecology, 22(2):203-212.

Souza, J. A. S. (2018). Produção de gramíneas forrageiras dos gêneros Urochloa e Megathyrsus nas condições edafoclimáticas de Manaus, AM. 58 f. Dissertação (Mestrado em Agronomia Tropical). Universidade Federal do Amazonas.

Recebido: 5 de fevereiro, 2019 .

Aprovado: 28 de fevereiro, 2019.

Publicado: 16 de março, 2019.

Licenciamento: Este artigo é publicado na modalidade Acesso Aberto sob a licença Creative Commons Atribuição 4.0 (CC-BY 4.0), a qual permite uso irrestrito, distribuição, reprodução em qualquer meio, desde que o autor e a fonte sejam devidamente creditados. 